\title{
Applying Holland's Vocational Choice Theory in Sport Management
}

David Pierce and James Johnson

This is the author's manuscript of the article published in final edited form as:

Pierce, D., \& Johnson, J. (2017). Applying Holland's Vocational Choice Theory in Sport Management. Sport Management Education Journal, 11(2), 72-87. https://doi.org/10.1123/smej.2016-0015 


\begin{abstract}
Holland's (1997) vocational choice theory is used in vocational counseling to aid job seekers in finding occupations that fit their personality based on Holland's RIASEC typology of personalities and work environments. The purpose of this research was to determine the Holland RIASEC profiles for occupations within the sport industry by having employees in intercollegiate athletics complete the Position Classification Inventory (Gottfredson \& Holland, 1991). Results indicated the three-letter Holland code for the sport industry is SEC. The sport industry is dominated by the Social environment, evidenced by seven occupations possessing Social in the first letter of the profile and Social rating in the top two for all occupations. Seven occupations were primarily Social, three were Realistic, two were Enterprising, and two were Conventional. A MANOVA was also conducted to compare differences between occupational disciplines on the six Holland environments. Implications for sport industry occupations and the application of Holland's theory are discussed.
\end{abstract}

Keywords: person-environment fit, intercollegiate athletics, personality, sport management careers, vocational counseling 
Applying Holland's Vocational Choice Theory in Sport Management

Determining if an individual is a fit for an occupation is critical for job seekers, hiring managers, and those providing vocational guidance (Hughey \& Hughey, 2009). The degree of similarity between a person and environment is the key measure in the theory of personenvironment fit (PE Fit; Chartrand, Strong, \& Weitzman, 1995). PE Fit is the compatibility between an individual and work environment that develops when congruence exists between one's individual characteristics and the environment in which he or she works or wishes to work (Kristof, 1996). PE fit has been shown to predict key organizational outcomes such as satisfaction and performance (Nauta, 2010). In a meta-analysis of over 60 years of research, Nye, Su, Rounds, and Drasgow (2012) found that the level of congruence between an individual and the environment was a strong predictor of performance criteria (e.g., task performance, organizational citizenship behavior, persistence). Vocational psychology has produced a variety of theories and corresponding assessment instruments that facilitate the match of individuals' characteristics with the characteristics of the work environment. Holland's theory of vocational choice is a major force in vocational psychology and serves as a foundation for many other interest inventories that match individuals to work environments (Nauta, 2010; Spokane, Luchetta, \& Richwine, 2002). While the application of Holland's theory has produced thousands of work environment profiles that are used to match an individual's score on a personality profile to best-fit occupations, sport management is not identified in Holland-related publications because it is not a specific occupation.

The broad nature of sport management with its varied occupational disciplines presents a fundamental problem because declaring that one wants to work in sport management fails to produce a clear picture of what occupation best fits that individual (Hancock \& Greenwell, 
2013). The field is far too broad to develop one profile that can capture the entire industry because job seekers might pursue employment in very different career tracks in areas such as marketing, finance, management, sales, communications, event management, and law. As a result, it is difficult for job seekers, hiring managers, and those providing vocational guidance to leverage Holland's theory to achieve PE fit. Beyond this, it is unclear as to whether occupations listed in publications using Holland's theory accurately describe similar positions within the sport industry (i.e., is fundraising in sport the same as fundraising listed in Holland-theory publications?). This problem stems from the fact that data for Holland publications are taken from indirect sources in broad contexts. Collecting data directly from employees within a specific industry makes the results more accurate to those seeking vocational guidance in that industry. In addition, occupations such as compliance officers and team operations directors do not appear in Holland publications, and thus have never been evaluated specifically from the theoretical perspective of PE fit. Third, changes are routinely made to occupational profiles. For example, the Holland code for Fundraisers is ECA in one publication and SEC in another.

These problems contribute to sport management currently lacking a theoretical foundation upon which faculty members or career counselors deliver career advice regarding which occupations (e.g. marketing, development, sales) best fit an individual's needs. These problems are compounded by the broad nature of the sport industry and the varied career possibilities of sport management students. The lack of occupation-level career focus demonstrated by sport management students stands in stark contrast to other disciplines housed with sport management majors at colleges and universities. To illustrate, individuals advising Kinesiology students in Athletic Training or Physical Education typically prepare students for one job upon graduation - athletic trainer and physical education teacher. In addition, career 
advising for individuals interested in sport management can occur in academic settings where sport management students take courses primarily taught by faculty in other related disciplines (e.g., kinesiology, tourism, leisure, business, recreation). Faculty outside of sport management may neither have experience in sport management career opportunities, nor be able to provide appropriate advice to the growing number of sport management students in their purview (Schwab et al., 2013). In sum, sport management currently lacks a theoretical foundation upon which faculty members or career counselors deliver career advice regarding which specific sport occupations (e.g. marketing, development, sales) best fit an individual's needs. Research is needed to offer stakeholders useful data that can help job seekers find meaning in their career.

It is important to address these concerns in light of the job market that applicants may choose to enter. As sport management programs have steadily proliferated from approximately 100 in 1990 (Kjeldsen, 1990) to over 722 worldwide in 2014 (Pedersen \& Thibault, 2014), intense competition for jobs has led some critics to question how so many programs can adequately educate and place approximately 8,000 graduates each year into a competitive marketplace where the average applicant to job ratio exceeds 50 to 1 (Jones, Brooks, \& Mak, 2008; King, 2009; Mathner \& Martin, 2012, Teamwork Online, 2014). With the federal government and state legislatures pushing institutions to refine accountability metrics tied to outcomes such as student job placement, rather than inputs such as enrollments (Dougherty, Natow, Bork, Jones, \& Vega, 2013; Stratford, 2013), large undergraduate sport management enrollments may soon become a vulnerability for departments and institutions. Therefore, PE fit is important for all stakeholders of sport management programs.

This paper develops a career matching system rooted in Holland's theory that can determine the profile for occupational disciplines specifically in sport management. It makes a 
theoretical contribution by expanding the theory of PE fit and Holland's vocational theory to establish that Holland's typology can be applied within a specific industry segment that contains a broad range of occupational disciplines. Additionally, this work makes a contribution to sport management career advising practice by offering faculty, students, and career counselors with an empirical and theoretical basis from which to deliver career advice.

\section{Literature Review}

Students are attracted to sport management based on their interest in and love of sports (Chen Adams-Blair, \& Miller, 2013; Hancock \& Greenwell, 2013; Mathner \& Martin, 2012; Schwab, Dustin, Legg, Timmerman, Wells, \& Arthur-Banning, 2013; Todd \& Andrew, 2008). For example, Hancock and Greenwell (2013) found that Interest in Sport was the highest rated major selection factor. Todd and Andrew (2008) found that students were attracted to careers in sport based upon a perceived PE Fit with the sport industry that was generated from the

perceptions of prestige and individual student' interest in sports. While students are attracted to sport management due to their love and interest in sport, students are not as committed to the management-related functions within the sport industry. Schwab et al. (2013) found that sport management students are unsure of their career goals and reasoned that students may be driven by a general passion for sport more than a specific career path. Hancock and Greenwell (2013) reached a similar conclusion noting that students are attracted to sport management based upon their love of sport, but not necessarily the management of sport. In short, students appear to be attracted to the first word of the major (sport) and not the second word (management). The question arises, then, about whether an individual's perceived fit in the sport industry is based on the industry as a whole, or based on the specific occupational context in which the individual works. Is it enough to say that an individual is a fit for sport management, or is further 
clarification needed on whether the individual is a fit for marketing, sales, event management, etc. based on the characteristics of the individual and occupation? With these questions in view, potential occupational areas that achieve PE Fit should be earnestly investigated throughout one's professional career using theories such as Holland's theory of vocational choice (Ross \& McCullough, 2014).

\section{Holland's Theory of Vocational Choice}

Holland's (1997) theory of vocational choice is widely accepted in vocational psychology (Nauta 2010). According to Holland (1997), "People search for environments that will let them exercise their skills and abilities, express their attitude and values, and take on agreeable problems and roles" (p. 4). The closer a person's personality fits their occupational environment, the more likely that person will be satisfied, productive, and remain in the job (Holland, 1997). Holland's theory is unique in that it provides a parallel way to describe both people and the environments in which they work (Gottfredson \& Richards, 1999). Holland (1997) classified persons and work environments according to six model types (RIASEC), which are defined in Figure 1: Realistic (R), Investigative (I), Artistic (A), Social (S), Enterprising (E), and Conventional (C). Visually, Holland (1997) arranged the six types of personalities and environments on a hexagon where the types adjacent to one another are more similar than they are to types more distant on the hexagon.

$<$ Insert Figure 1 about here >

Holland's six personality types represent "characteristic patterns of interest, competencies, and behavior" (Gottfredson \& Richardson, 1999, p. 57), while the six parallel environmental models are "settings that elicit, develop, and reward the six patterns of interest, competencies, and behaviors (p. 58). For example, Realistic personalities enjoy working with 
machines because they perceive themselves as having mechanical and technical abilities, but lacking some social skills. They seek work environments that encourage people to use machines or tools, demonstrate technical skills, and do not emphasize social skills. Thus, realistic types populate realistic jobs because the environment rewards realistic interests and behaviors.

People and environments resemble all six Holland types to some degree, and possess a unique combination of all six types. Each individual and occupational environment is assessed to determine their unique Holland letter code (see forthcoming section Application of Holland's Theory in Career Counseling). The highest two or three letters are used to match people with environments. So, if an individual's three-letter code matches the work environment's threeletter code, there is an increased level of congruence whereby the individual's skills and interests would be appropriately matched to their work environment improving satisfaction, stability, and achievement (Holland, 1997).

In addition to the RIASEC profile scores and the three-letter Holland code, occupations are also described in terms of consistency and differentiation. Consistency is a measure of the internal coherence of an occupation's Holland environment scores. It is determined by the proximity of the first two letters on the hexagon. For example, RI (adjacent on the hexagon) has a high level of consistency, RA (one-level difference) has a middle level of consistency, and RS (two-level difference) has low consistency. Differentiation describes the extent to which a person or environment resembles one of the types exclusively, or resembles all six types to the same degree (Gottfredson \& Holland, 1991). The highest differentiation score occurs when one person or environment resembles only one type, while the lowest differentiation score occurs when the person or environment has identical scores on all six types.

Individuals complete Holland's Self-Directed Search (SDS) (Holland \& Messer, 2013b) 
to determine their three-letter code and then utilize publications that identify specific occupations congruent with the personality profile identified in the SDS (Nauta, 2010). The Occupations Finder (OF) (Holland \& Messer, 2013c), accompanies the SDS and identifies the three-letter Holland code for the 1,400 most common occupations in the United States. The OF has continued to be updated and has somewhat replaced the Dictionary of Holland Codes (DHOC) (Gottfredson \& Holland, 1996), which has not been updated since 1996. Users investigate occupations with the same three-letter code and then rearrange their code letters in all possible ways to explore occupations under those three-letter codes. The Holland codes found in the $O F$ and $D H O C$ are also linked to the O*NET database of occupational information made accessible by the federal government through O*NET (O*NET Online, 2015). The United States Department of Labor developed O*NET to collect, organize, describe, and disseminate data on occupational characteristics and work attributes, including occupational interest profiles based on Holland's theory (Rounds et al., 1999). The OF and O*NET database are regularly updated and work hand-in-hand to help job seekers find occupations congruent to their personality.

\section{Determination of Occupational Holland Codes}

Rounds, Smith, Hubert, Lewis, and Rivkin (1999) outlined the three methods used to determine occupational codes. The incumbent method uses employees' RIASEC interest scores from the SDS to code occupations. The empirical method uses occupational data provided by the Department of Labor to assign RIASEC codes through classification equations that estimate the probability each of the occupations belong to each category. The judgmental method utilizes trained judges to analyze an occupational description and select the most appropriate RIASEC ordering. Initial efforts to classify occupations in the 1990s relied on the empirical approach, while more recent updates have relied on trained judges to make assessments on thousands of 
occupations (Rounds et al., 1999; Rounds, Su, Lewis, \& Rivkin, 2013).

While the codes imputed to occupations have been shown to be fairly reliable,

Gottfredson and Holland (1991) cautioned that occupational classifications should be regarded as approximations because they are based on fallible data, some occupations are not included in the classification, the nature of demands of occupations vary from organization to organization and industry to industry, and they fail to provide a way to directly assess a specific position or occupation. For example, the occupational classifications in the DHOC, OF, and O*NET provide no method for determining if a sport marketer is different from a marketer in a general business setting. Additionally, occupations like equipment manager, video coordinator, and compliance officer have no direct DHOC or O*NET equivalent. Gottfredson and Holland (1991) developed the Position Classification Inventory (PCI) to remedy these shortcomings. The PCI is a method for directly classifying any position or occupation according to Holland's typology by having employees describe the work environment via a 78-item questionnaire. While the PCI provides a reliable method for directly classifying occupations, one major disadvantage is the expense and time of collecting data from large representative samples in thousands of occupations (Rounds, Smith, \& Hubert, 1999). These difficulties explain why the PCI has not been used to define Holland codes in a general database like the O*NET, but are extremely valuable used in a study like this to classify specific occupational environments Generating the Holland code directly from employees working in a specific occupation within a specific context based on their assessment of work environment using the PCI solves two key shortcomings of the empirical and judgmental methods. First, these methods rely on indirect measures and fail to account for variations within industries and contexts (Gottfredson \& Holland, 1991). Second, these indirect methods have been used due to the expensive and time 
consuming process of collecting data from workers in thousands of occupations that would exist using the PCI (Rounds et al., 1999). However, collecting data directly from employees working within a specific industry context (i.e., using the PCI) is preferable. Collecting PCI data within a specific industry contexts creates clarity for stakeholders using Holland's theory in assessing PE fit, which addresses the key challenges faced in sport management discussed in the introduction.

\section{Purpose}

In light of the advantages to using the PCI to determine the RIASEC profile for occupations by directly surveying employees, as well as the challenges of career advising in sport management, the purpose of this study was to extend the theories of PE fit and Holland's vocational theory by determining the Holland RIASEC profiles for occupations within the sport industry. College athletics was chosen because it contains a large cross section of the occupations in which individuals seek employment in the sport industry. While college athletics does not produce a comprehensive listing of every possible job in the sport industry, it does provide a reasonable sample from which to collect data using the PCI. Specifically, this study answers the following research questions:

1. What is the nature of the RIASEC profile for the intercollegiate athletics industry and for each occupation (profile of scores, three-letter code, consistency, and differentiation)?

2. Do the sport management occupational disciplines differ from each other on each of the six Holland environments?

\section{Methods}

\section{Procedure and Sample}

An email database of 6,000 employees in college athletics was constructed by randomly selecting four schools from each conference in each NCAA Division. If an institution did not 
have email addresses available on its website, another institution was randomly selected from the conference. Individuals were invited to participate in an online survey (Qualtrics) through two emails distributed one week apart during the middle of the fall semester. A total of 1,753 emails were opened (29\%). A total of 575 individuals completed the survey, which represented $9.6 \%$ of the database and $32.8 \%$ of the emails that were opened. Males accounted for $57.6 \%$ of the sample, employees at Division I institutions accounted for $62.2 \%$, and respondents on average had worked in college athletics for 10.6 years $(S D=9.2)$.

\section{Measures}

Position Classification Inventory. The PCI provides a method for classifying any position or occupation according to Holland's typology of work environments (Gottfredson \& Holland, 1991). Employees describe the demands, rewards, values, fostered competencies, and opportunities for expression of abilities in the work environment through answering questions on a 78-item inventory. Each environmental model is represented by 13 items to which respondents answer Often, Sometimes, or Never. Respondents were asked to indicate such things as: (a) what people are required to do in their job (e.g., use power tools); (b) the skills, abilities, and personal characteristics exercised (e.g., clerical skill); (c) the outlook or perspective demanded (e.g., factfinding); (d) the personal styles or values expressed or met (e.g., working outdoors); (e) the personal characteristics required (e.g., intellectual); (f) the abilities, skill, or talents needed by a person (e.g., creativity); (g) and the extent to which certain activities are engaged in (e.g., solve scholarly or technical problems). The Often response was scored one, the Never response was scored zero, and the Sometimes response was scored one for some and zero for others based on the scoring key provided in the PCI. The results produce a profile of scores from 0 to 13 across the six environments (RIASEC) for each occupational discipline. 
The psychometric properties, validity, and reliability of the instrument have been established in several studies (Gottfredson \& Holland, 1991; Maurer \& Tarulli, 1997). The PCI has been used in previous studies to examine the work environment of specific occupations such as customer service representatives (Fritzsche, Powell, \& Hoffman, 1999), nonprofessional occupations (Chauvin, Miller, \& Eaton, 2011), managerial jobs (Maurer \& Tarulli, 1997), and occupational subspecialties (Upperman \& Church, 1995). The reliability of the scales in the current study were measured with Cronbach's alpha and exceeded the recommended value of 0.70 for all six environments, ranging from .74 to .92 .

Occupational disciplines. Respondents were asked to identify which occupational discipline best described their role within the athletic department. If they had dual roles, they were asked to select the role that was most prominent in their job. The 15 occupational disciplines were developed by examining the professional associations offered within the National Association of Collegiate Directors of Athletics and the job titles and functional departments listed on athletic department websites. The final list of occupational disciplines was also reviewed by sport management faculty members with an expertise in college sports. Fourteen of the fifteen occupational disciplines recorded at least ten responses, meeting Gottfredson and Holland's (1991) requirement of ten responses per occupation. Only Licensing failed to meet the minimum threshold, and it was thus excluded from the study.

\section{Data Analysis}

The data were analyzed using the Statistical Package for the Social Sciences version 22.0. Eight cases were removed from the sample for the following reasons: four univariate outliers were greater than three box-lengths from the edge of the box, and four multivariate outliers possessed Mahalanobis b values greater than 22.46. The removal of these cases and the two 
responses from Licensing yielded a total of 565 cases subjected to analysis. The data met skewness, kurtosis, and multicollinearity assumptions.

To compare differences between occupational disciplines on the six Holland environments, a MANOVA was conducted with the Holland environments as dependent variables and occupational discipline as the independent variable. Because four of the six dependent variables failed Levene's test of equality of error variances in the follow-up one-way ANOVA, the non-parametric Kruskal-Wallis test for all six dependent variables was utilized. Pairwise comparisons were performed on significant results using Dunn's (1964) procedure with a Bonferroni correction for multiple comparisons.

To determine the three-letter Holland code for each occupational discipline, the top three environment scores were used. In the event that the fourth highest score is less than 0.1 from the third highest score, it was noted on the summary table. Consistency was determined by evaluating the proximity of the first two letters on Holland's hexagon. Differentiation was calculated using one of Iachan's (1984) family of indices: $D=\left(\mathrm{X}_{1}-\left(\mathrm{X}_{2}+\mathrm{X}_{4}\right) / 2\right)$, where $\mathrm{X}_{1}$ is the score for the highest profile, $\mathrm{X}_{2}$ is the score for the second highest profile, and $\mathrm{X}_{4}$ is the score for the fourth highest profile. Differentiation indices greater than 2.0 are considered well defined, highly differentiated; 1.0 - 1.99 as moderately defined, moderately differentiated; and less than 1.0 as not well defined, undifferentiated (Gottfredson \& Holland, 1991).

\section{Results}

\section{Research Question 1}

The first research question investigated the nature of the RIASEC profile for the intercollegiate athletics industry and for each occupation (profile of scores, three-letter code, consistency, and differentiation). The descriptive summary of Holland work environment scores 
for each occupational discipline and the overall score for college athletics is presented in Table 1. The Holland diagnostics of overall code (top 3 letters), consistency (using the first two letters), and differentiation (profile scores) are presented in Table 2, which are based off the results of Table 1. The overall Holland code for college athletics is SEC, and 10 of the 14 occupational disciplines possessed some combination of Social, Enterprising, and Conventional. Social was the first letter in 7 occupational disciplines, and it was in the top 2 letters for all 14 occupational disciplines. Conventional was in the top three letters for all disciplines except athletic trainer and video. Enterprising was in the top three letters for all disciplines except athletic trainer and equipment manager if the third-letter ties are considered. The strongest Realistic environments were equipment manager, event and facility management, and video. The strongest Conventional environments were business management and compliance. The strongest Enterprising environments were marketing and sales.

The overall sport industry code demonstrated high consistency with Social and Enterprising as the first two letters. The lowest consistency was observed in the four occupations with Realistic and Social in the first two letters - athletic trainer, equipment manager, event and facility management, and video. Five disciplines matched the overall code of SEC - athletic director, development, sports information, team operations, and ticketing. Analysis of differentiation scores did not reveal any occupational disciplines that were well defined. Nine of the disciplines were moderately defined and five were undifferentiated. The strongest defined occupational discipline was academic advisement, while compliance and event/facility management were the least defined.

$<$ Insert Tables 1 and 2 about here >

\section{Research Question 2}


The second research question investigated whether sport management occupational disciplines differed from each other on each of the six Holland environments. A MANOVA compared differences between occupational disciplines on the six Holland environments. The differences between the occupational disciplines on the combined dependent variables were statistically significant (Pillai's Trace $=1.705, F(6,78)=16.819, p<.001$, partial $\eta^{2}=.284$ ). Follow-up univariate ANOVAs revealed four of the six dependent variables lacked homogeneity of variance, as assessed by Levene's test. To compensate for unequal variance, the KruskalWallis non-parametric procedure was employed to determine if there were differences in Holland scores between the occupational disciplines. Distributions of Holland scores were similar for all groups, as assessed by visual inspection of a boxplot. All six Holland scores were significantly different between the occupational disciplines at $p<.001$. Pairwise comparisons using Dunn's (1964) procedure with a Bonferroni correction for multiple comparisons revealed that 128 of 546 (23.4\%) occupational comparisons were statistically significant from each other.

Table 3 presents the results for the Realistic environment. Occupational disciplines with a mean greater than 10 (equipment manager, athletic trainer, event and facility management, and video) were significantly more Realistic than those less than 6 (ticketing, business management, sales, development, academic advisement, and compliance). Table 3 also presents the results for the Investigative environment. Athletic trainer was statistically the most investigative discipline, followed by compliance. The least Investigative disciplines were equipment manager, event and facility management, ticketing box office, and video. Table 4 presents the results for the Artistic environment. Occupational disciplines with a mean greater than 7 (marketing, sports information, and video) were significantly more artistic than those less than 5 (event and facility management, business management, compliance, and ticketing). 
Table 4 also presents the results for the Social environment. Occupational disciplines with means greater than 11 (academic advisement, athletic director, development, athletic trainer) were significantly more social than those less than 9.7 (sports information, compliance, business management, video, and in some cases marketing). Table 5 presents the results for the Enterprising environment. In general, the most Enterprising disciplines were sales, development, athletic director, marketing, and ticketing with means greater than 10, while the least enterprising disciplines were event and facility management, academic advisement, equipment manager, compliance, athletic trainer, business management, and video with means less than 9. Finally, Table 5 also presents the results for the Conventional environment. Compliance was the most Conventional and significantly greater than athletic trainer, development, marketing, and video. Video was the least conventional environment.

\section{$<$ Insert Tables 3-5 about here >}

\section{Discussion}

By establishing how Holland's theory and administration of the PCI can be applied to distinct occupations within the same industry, this study offers a theoretical underpinning for career advising by empirically developing Holland codes for occupations within sport management to supplement occupational information found in $\mathrm{O}^{*} \mathrm{NET}, \mathrm{DHOC}$, and $O F$. The results make evident sport management is too broad and diverse for a single Holland code, substantiated by seven Social, three Realistic, two Conventional, and two Enterprising occupation types.

\section{Industry Code}

The three-letter Holland code for the intercollegiate athletics industry is SEC. It exhibits high consistency with the Social and Enterprising environments adjacent on Holland's hexagon, 
and moderate differentiation as measured by the Differentiation Index of 1.3. Employment in intercollegiate athletics is dominated by the Social environment, outpacing the Enterprising environment by 1.49 (see Table 1). Not only did Social score higher on average than any of the other environments, but Social was the top environment for seven occupations, and it was in the top two environments for all occupations. The Social environment is defined by skills in mentoring, treating, healing, or teaching others and rewards the expression of concern for the welfare of other people. Social occupations involve working with people in helpful ways.

The strength of the Social environment expressed within intercollegiate athletics is not a surprise given the sport industry has been routinely identified as a service-centric industry (Chelladurai, 2009; Lovelock \& Gummesson, 2004). Delivering consumer and professional services through a variety of social interactions is commonplace within sport managementrelated occupations. Within college athletics the primary driver on the Social environment is the role athletic department employees play in helping student-athletes achieve on the field, in the classroom, and life. For occupational disciplines not directly assisting with the student-athlete experience, employees are either helping coaches perform, or they are helping stakeholders (fans, donors) engage with the athletic department through the event experience or financial gifts. These varying services provided by intercollegiate athletic administration and staff are examples of the critical role the social component plays in service industries (Chelladurai, 2009).

Five occupations were an exact match to the overall industry profile of SEC, and another five were some combination of Social, Enterprising, and Conventional (SCE, ESC, CSE). These three environments are adjacent to each other on the hexagon, demonstrating consistency within the overall three-letter code. However, it is important to note that Enterprising and Conventional were essentially a tie (see Table 1), with Enterprising scoring only 0.21 greater than 
Conventional. Enterprising was in the three-letter code for 10 occupations and scored higher than Conventional in eight, while Conventional was in the three-letter code for 12 occupations and scored higher than Enterprising in six. As a result SCE could be as reasonable as SEC. Regardless of whether the code is SEC or SCE, these codes differ from the ESR code reported for sport management majors in the Educational Opportunities Finder (Holland \& Messer, 2013a) and university websites.

\section{Social Occupations in College Athletics}

Athletic director. Athletic director was the second highest Social environment trailing only academic advisement, and it was significantly more Enterprising than half of the occupations (see Table 5). It was a close match to the SER code listed in the OF, and more Social than the EC profile for chief executives in O*NET. The unique aspect for athletic directors is the focus on helping student-athletes achieve on and off the field of competition while overseeing the managerial components that require refined communication skills and an entrepreneurial spirit. When one considers the amount of stakeholders an athletic director must engage (e.g., fans, donors, students), as well as any facility and human resource changes they must navigate, the Social and Enterprising characteristics appear indispensable.

Ticketing/box office. The ticket manager is responsible for managing the sale and distribution of game tickets, which includes printing, selling, managing inventory, distributing, and reconciling tickets and money (Gauthier, 2009). Ticketing/box office scored significantly less than other occupations on the Realistic, Investigative, and Artistic environments, but scored significantly higher on Enterprising and Realistic. Even though the strongest environment was Social, it was not significantly higher than other occupations on the Social environment. Because the job responsibilities for ticketing and box office professionals is broader than 
processing transactions at the gate, the Conventional environment is tertiary unlike the $\mathrm{CE}$ profile for Cashier in O*NET. A closer match is found with "Ticket Taker" listed as SCE in O*NET. The occupation is also distinct from sales, which was more Enterprising in light of the need to proactively pursue new business through prospecting, setting appointments, and giving sales presentations, rather than reactively processing sales as requested by customers.

Development. Development officers raise funds in the athletic department through the identification, cultivation, solicitation, and stewardship of annual, major, and planned gifts (Gauthier, 2009). The development of relationships with donors is fundamental to the job of a development officer (Gladden, Mahony, \& Apostolopoulou, 2005), with nearly equal importance on persuading donors to give money to achieve organizational objectives (Enterprising). As might be expected, development scored significantly lower on Realistic and significantly higher on Social and Enterprising than other occupations. The results of this study confirm the SEC code published in the DHOC and OF as opposed to the ECA code in O*NET. The fact that athletic directors and development officers have the same Holland profile helps explain why the ability to fundraise is an important characteristic for college athletic directors and why development is the most common background of recently hired athletic directors (Wong, 2014). Sports information. Sports information, also termed Media Relations, is responsible for the creation and distribution of information to the media and other external publics through media guides, game programs, news releases, press conferences, statistics, photography, website, and social media (Gauthier, 2009). The sports information occupation demonstrated an undifferentiated profile evidenced in the small differential (2.53) between the strongest environment (Social) and the fifth environment (Realistic). While Social was the leading environment, sports information was significantly less Social than four other occupations. In 
contrast, Artistic was the fourth strongest environment, but sports information was the second most Artistic occupation and significantly more Artistic than six occupations. It is also important to note the virtual tie between the Enterprising and Conventional environments, which means the three-letter code for sports information could just as reasonably be SCE. In short, sports information demonstrates relatively strong shades of five environments, which may be reflected in event and game management responsibilities entrusted to sports information directors, particularly at smaller institutions. Finally, the code is substantially different from the EAS code for "Public Relations Specialist" in O*NET. The inclusion of Conventional in the three-letter code for sports information likely stems from tracking team and individual statistics.

Team operations. Team operations personnel are responsible for coordinating travel, recruiting operations, and other services for specific teams. Those in team operations positions may be pursuing a career in coaching, or may be in a general athletics administration role that requires a multitude of skills encompassing social (athlete recruitment), conventional (coordinating team travel), and enterprising (general management). Team operations possessed an undifferentiated profile, as evidenced by the small difference between the top four profiles (SECR). Team operations had no significant differences on five of the six environments. The diversity of responsibilities for those in team operations positions likely explains the undifferentiated profile.

Academic advisement. Academic advisement was also defined by the Social environment (SCE). Academic advising professionals are responsible for a variety of tasks including course advisement, academic counseling, monitoring the academic progress of student-athletes, coordinating tutorial programs, and maintaining accurate records (Gauthier, 2009). Academic advisement scored the highest on the Social environment, and it possessed the most clearly 
defined profile. These results are not surprising considering the primary function of academic advising is to work directly with student-athletes and coaches to help student-athletes navigate the rigors of college. Johnson (2013) noted that academic advisors must be well versed in many specialized areas to intervene with appropriate support services, and that interpersonal interaction is a routine part of delivering these services. These duties certainly require a strong social element often found in other helping professions. For example, $\mathrm{O}^{*} \mathrm{NET}$ and $\mathrm{OF}$ note that guidance counselors in educational settings are Social occupations.

Athletic training. Athletic training is defined by the Social environment. Athletic trainers are the sports medicine professionals within the athletic department responsible for the prevention, care, and rehabilitation of athletic injuries (Gauthier, 2009). Athletic trainer was the only occupation to include the Investigative profile in the three-letter code, and it was the highest scoring Investigative occupation, significantly more Investigative than every occupation except compliance and team operations. It was also more Realistic than over half of the occupations. The results from this study match the SRI code noted in O*NET. Based on the SRI profile, athletic trainers first and foremost help athletes perform at the highest level possible by preventing and caring for their injuries. Athletic trainers also work with their hands and with tools while diagnosing injuries of the athletes. Athletic training is the only SRI occupation likely due to different educational requirements for athletic trainers compared to sport administrators.

\section{Enterprising Occupations in College Athletics}

Marketing and sales. Marketing (ESC) and sales (ESC) were the two Enterprising occupations in college athletics. The Enterprising environment requires skills in the persuasion and manipulation of other people in the pursuit of financial gains and achievement of organizational goals. Ambition and self-confidence are rewarded in Enterprising environments. 
This description captures the fundamental purpose of sales and marketing, which is why nearly all marketing and sales related positions are categorized as Enterprising in $\mathrm{O}^{*} \mathrm{NET}$ and the $O F$. Specifically, nearly all sales positions fall under the ES profile, and Advertising and Promotions Manager, Sales Agent for a variety of industries, and Customer Service Representatives are ESC. Marketing and sales were significantly more Enterprising than a majority of the other occupations (see Table 5), and each showed separation from the Enterprising and Social environments to the third highest environment (see Table 1). The Enterprising nature of marketing positions is evident in the responsibility for increasing attendance, revenue, and visibility for the athletic department through coordination of advertising campaigns, corporate sponsorship, ticket sales campaigns, licensing, and promotional activities (Gauthier, 2009). Salespeople demonstrate an Enterprising environment by prospecting, giving sales presentations, closing sales, upselling, and providing customer service to enhance renewals for the next year (Pierce, Petersen, Clavio, \& Meadows, 2012). While both occupations noted Conventional as the third highest environment, each ranked at the bottom of Conventional occupations, although not statistically different. Both occupations possessed high consistency. Marketing was less defined as a result of a strong Artistic component, which trailed Conventional by only .02. In fact, marketing was the most Artistic occupation in the study. As a result, marketing could be defined by the ESA three-letter code as reasonably as the ESC code.

\section{Conventional Occupations in College Athletics}

Business management and compliance share similarities in job responsibilities and RIASEC profiles. The Conventional environment emphasizes clerical skills to meet precise standards of performance, values orderliness and routines, and rewards conformity. Conventional occupations "typically involve working with things, numbers, or machines in an 
orderly way to meet the regular and predictable demands of an organization or to meet specific standards" (Gottfredson \& Holland, 1991, p. 4). Compliance and business management possessed the same three-letter code (CSE), possessed Investigative as the fourth highest score, demonstrated low levels of Realistic and Artistic, and showed medium consistency. Both positions perform a watchdog role for the department to ensure teams and administrators follow protocol (Wong, 2009). Business managers play a key role ensuring transparency to the university and government, and compliance officers hold athletic departments accountable to NCAA legislation (Wong, 2009). The CSE code has face validity based upon other CSE occupations that include Accountants, Bookkeepers, and Internal Affairs Investigators.

Compliance. The compliance officer is responsible for working with all stakeholders to create a culture of compliance (Pierce, Lawrence, \& Kaburakis, 2011). The Conventional nature of compliance is seen in the responsibility to oversee of all aspects of conference and national rules for the athletic department, including initial and continuing eligibility and amateurism, rules education, reporting violations, maintaining squad lists, monitoring recruiting activities, and maintaining compliance monitoring procedures (Gauthier, 2009). While Social and Enterprising were the second and third highest environments, compliance was significantly less Social than academic advisement, athletic director, development, and athletic trainer. Additionally, compliance was significantly less Enterprising than sales, development, athletic director, and marketing. In contrast, while Investigative did not make the top three for compliance, compliance was significantly more Investigative than four occupations. The undifferentiated profile resulted from Investigative scoring close to Social.

Business management. Business management was the fourth most conventional environment, but did not demonstrate statistical significance over any other occupation. The 
Conventional nature of business management is seen in the responsibility to manage all financial aspects of the athletic department including preparing and monitoring budgets, prepare and analyzing financial statements and payroll records, forecast and monitoring of revenues and expenses, conduct oversight of equipment purchasing, and execute departmental travel policies (Gauthier, 2009). Similar to the profile for Compliance, business management was significantly less Social and Enterprising than other occupations despite their presence in the three-letter code.

\section{Realistic Occupations in College Athletics}

Equipment manager, event and facility management, and video were the three Realistic occupations in college athletics. Realistic environments require manual and mechanical competencies and interaction with machines, tools, and objects. Realistic occupations reward the display of practical, mechanical, technical, and physical abilities; conforming behaviors; and practical accomplishment (Gottfredson \& Holland, 1991). These three positions are good examples of jobs that do not translate to existing occupations on the $\mathrm{O}^{*} \mathrm{NET}$ or $\mathrm{OF}$, and makes this research valuable to those who might use this information to deliver career advice. All three occupations were significantly more Realistic than a majority of the other positions in college athletics (see Table 3), and they possessed the same two-letter profile (RS). The RS profile demonstrates low consistency because Realistic and Social are diametrically opposed to each other on the hexagon. Lack of internal coherence in these occupations occurs because the Realistic environment often involves work with machines or tools whereas the Social environment involves work with people. A highly inconsistent work environment requires a combination of interests that are rarely required in the same job, which leads to a smaller pool of employees with highly incongruent personalities (Nauta, 2013). 
Event and facility management. Event and facility managers in college athletics are responsible for the scheduling and maintenance of athletics facilities and managing events within the facilities (Gauthier, 2009). Duties may include game operations and production, managing rental contracts, marketing and public relations, budgeting and finance, and other functionallevel tasks to execute a successful event (Wong, 2009). Event and facility management represented a unique case because it possessed low consistency and was the least differentiated. For event and facility managers, it is apparent that Realistic, Social, Conventional, and Enterprising scored relatively high, and the scores between Realistic and Social, as well as scores between Conventional and Enterprising, were separated by relatively small amounts. In reality the three-letter codes SRC, SRE, and RSE could be as reasonable as RSC. The reason event and facility management demonstrated low consistency and differentiation is that individuals in these positions require a variety of different functional-level tasks that strongly cross over into four different Holland types. While ushers, security, concessionaires, and traffic managers may have better defined work environments based on the specific nature of their role, the event and facility manager has a more over-arching management responsibility.

Equipment manager. Equipment managers (RSC) demonstrated the third highest differentiation score, trailing only academic advisement and sales. The equipment manager is responsible for purchase, maintenance, inventory, and record keeping of the equipment used by teams. The clearly defined Realistic nature of equipment managers is evident in that equipment managers work in a "real hands-on position that will include the daily pickup of practice gear, cleaning the gear, and distributing it back to the teams for their next practice" (Gauthier, 2009, p. 23). The low consistency observed in equipment manager positions stems from the fact that while equipment managers must perform many realistic functions on the job (i.e. laundry, 
uniform distribution and retrieval, moving equipment for practice and game day), they are doing so in an environment where they are catering to coaches and athletes.

Video. Individuals in video services use technology to produce multimedia content for the athletic department used on video boards, coaches' shows, television advertisements, social media video packages, live-event web streaming, and highlight videos. On a smaller scale, some individuals working in video provide technical video services for a specific team and focus on taping practices and games and assist in video content delivery for strategy and recruiting. Video was unique amongst the occupations included in this study because of the presence of the Artistic environment. Video was the only occupation to possess Artistic in its three-letter code. Marketing and Sports Information scored higher on Artistic than video, but Artistic was not in the top three for either of those areas. Additionally, video's three-letter code of RSA is unique because the DHOC and O*NET do not identify any RSA occupations. All three environments can be observed in the use of video editing and production software to create multimedia content for athletic departments. Working in video requires manipulation of camera and technological equipment to capture the visual footage (Realistic) used in post-production (Artistic) to distribute content used by coaches, marketing, sports information, and administrators (Social).

\section{Impact on Sport Management Education}

Sport management programs prepare students for jobs in the sport industry by informing them about the realities of a sports career (Pierce, Wanless, \& Johnson, 2014), directing them towards specific career goals that meet their individual needs (Todd \& Andrew, 2008), engaging students in field experiences (Foster \& Dollar, 2010), and providing guidance on career decisions (Hutchinson, Sagas, \& Quatman, 2010). Faculty members are uniquely positioned to help students navigate the difficult job market and to help individuals identify which career path 
would best fit their personality, interests, and skills - regardless of whether advisement is a component of their official duties. Guidance from faculty is essential to help students understand competition for jobs, salaries, and desired employee characteristics (Mathner \& Martin, 2012). It is not uncommon for faculty to meet students "uncertain of the most effective and efficient path to follow in the attainment of their desired profession" (Hutchinson et al., 2010, p. 561).

The results of this study impact career advising of sport management students. The starting point for using Holland's theory for career advising is the determination of the student's three-letter Holland code. Determining one's Holland code is part of the self-awareness and occupational exploration process in career planning (Ross \& McCullough, 2014). Students can take the SDS online for less than $\$ 10$ or complete a variety of different interest inventories that are available for free through the university's career services website. Analysis of the student's three-letter code and differentiation profile can be compared to the results of this study to find the best fit for their personality and interests in the sport industry. The one-on-one advising setting is one forum for this discussion to occur, in addition to resources that may be provided through the university's career center. However, while university career counselors can be helpful in writing resumes and cover letters, preparing for interviews, developing a professional portfolio, and bolstering a social media presence, sport management faculty members should be better positioned to help students match their strengths to the discipline-specific nature of work in sport industry occupations. While it is beyond the scope of this paper to deliver a full tutorial on the utilization of the Holland code, there are a few key points to keep in mind. First, a work environment does not have to be completely congruent with a student's personality to be rewarding (Nauta, 2013). Students should be encouraged to consider all combinations of their three-letter code. Second, congruence is one of many sources of information that should be 
considered when matching students to environments (Nauta, 2013). In other words, the Holland code is not the only source of information available to assist students in making career choices. This reality has implication for the management of sport management programs.

Utilization of the Holland code in the context of a broader career planning strategy should be thoughtfully and intentionally implemented across the curriculum. While implementation may vary depending on institutional context, key checkpoints for self-assessment during the student's college experience would likely include courses such as Introduction, Career and Leadership Principles, Practicum, Internship, and any course that includes an experiential or service learning component. These courses should ask students to reflect on their experience in the field or their results to any type of career assessment, including their Holland profile. Performance assessments can also be gathered from industry partners and site supervisors. The key point is that the student's Holland code is but one data point amongst a diverse array of other data points that draw conclusions about interests, personality, sources of satisfaction, and performance. Students should be encouraged to accumulate these data points and documents in an electronic portfolio to bring coherence to their academic experience (Gentile, 2010) and provide a one-stop shop for the career advisor to understand the needs and interests of the advisee.

The results also impact the management of sport management programs. For the recruitment of incoming students, the results of this study can help in the development of marketing materials that describe the nature of the sport industry in the most accurate way. For example, the SEC profile in this study differs from the commonly promoted ESR profile for the sport management major. Sport management programs can best position themselves to receive students who are changing their major by creating a presence in majors a similar Holland-code. Institutional context will dictate the methods used to create this presence, but there will be a 
higher yield of change-of-major students from majors with a similar Holland code. The same principle applies when attempting to recruit an interdisciplinary group of students to execute an experiential, service, community-based, or immersive learning project with an industry partner.

\section{Limitations and Future Research}

This study focused on college athletics, which may not be generalizable to the entire sport industry. Future research will be extended to other employment areas of the sport industry (i.e. professional sports, recreation, agencies) and other occupational disciplines not represented in this study (i.e. scouts, general manager). Additionally, once a comprehensive set of Holland codes are developed for the sport industry, PE Fit (congruence) of employees should be assessed in relation to job satisfaction, stability, and performance.

\section{Conclusion}

The results of this study using the PCI to determine the RIASEC profile of sport industry occupations is important to the field of sport management because (1) the entire field of sport management cannot be described using just one Holland code; (2) several occupations have a significantly different Holland code within the sport industry compared to the existing OF, DHOC, and O*NET; and (3) several sport industry occupations do not have equivalents in the OF, DHOC, and O*NET. The results of this study provide students, faculty, employers, job seekers, employees, and researchers with a framework to understand the unique work environments in the sport industry that could ultimately serve to match skills and interests to the most appropriate sport occupation. 


\section{References}

Chartrand, J., Strong, S., \& Weitzman, L. (1995). The interactional perspective in vocational psychology: Paradigms, theories, and research practices. In W. B. Walsh \& S. H. Osipow (Eds.), Handbook of vocational psychology ( $2^{\text {nd }}$ ed., pp. 35-66). Mahwah, NJ: Lawrence Erlbaum Associates.

Chauvin, I., Miller, J., \& Eaton, K. (2011). The application of Holland's theory to a nonprofessional organization. Individual Differences Research, 9(4), 231-237.

Chelladurai, P. (2009). Managing organizations for sport and physical activity ( $\left.{ }^{\text {rd }} \mathrm{ed}\right)$. Scottsdale, AZ: Holcomb Hathaway.

Chen, S., Adams-Blair, H., \& Miller, A. (2013). Professional expectations of sport management students as related to academic curricular alignment support and preparation. Universal Management Journal, 1(3), 132-137.

Dougherty, K., Natow, R., Bork, R., Jones, S., \& Vega, B. (2013). Accounting for higher education accountability: Political origins of state performance funding for higher education. Teachers College Record, 115, 1-50.

Dunn, O. (1964). Multiple comparisons using rank sums. Technometrics, 6(3), 241-252.

Foster, S., \& Dollar, J. (2010). Experiential learning in sport management: Internships and beyond. Morgantown, WV: Fitness Informational Technology.

Fritzsche, B., Powell, A., \& Hoffman, R. (1999). Person-environment congruence as a predictor of customer service performance. Journal of Vocational Behavior, 54, 59-70.

Gauthier, H. (2009). The ultimate guide to getting hired in college sports. Meridian, ID: Sport Leadership Publishing Company.

Gentile, D. (2010). Teaching sport management: A practical guide. Sudbury, MA: Jones and 
Bartlett Publishers.

Gladden, J., Mahony, D., \& Apostolopoulou, A. (2005). Toward a better understanding of college athletic donors: What are the primary motives? Sport Marketing Quarterly, 14, $18-30$.

Gottfredson, G., \& Holland, J. (1991). The position classification inventory: Professional manual. Odessa, FL: Psychological Assessment Resources.

Gottfredson, G., \& Holland, J. (1996). Dictionary of Holland occupational codes (3 ${ }^{\text {rd }}$ ed.). Lutz, FL: Psychological Assessment Resources.

Gottfredson, L., \& Richards, J. (1999). The meaning and measurement of environments in Holland's theory. Journal of Vocational Behavior, 55, 57-73.

Hancock, M.G., \& Greenwell, T.C. (2013). The selection of a sport management major: Factors influencing student choice from a consumer-oriented perspective. Sport Management Education Journal, 7, 13-24.

Holland, J. (1997). Making vocational choices: A theory of vocational personalities and work environments (3rd ed.). Odessa, FL: Psychological Assessment Resources.

Holland, J., \& Messer, M. (2013a). Educational opportunities finder (5 $5^{\text {th }}$ ed.). Lutz, FL: Psychological Assessment Resources.

Holland, J., \& Messer, M. (2013b). Self-directed search (5 $5^{\text {th }}$ ed.). Lutz, FL: Psychological Assessment Resources.

Holland, J., \& Messer, M. (2013c). The occupations finder ( $5^{\text {th }}$ ed.). Lutz, FL: Psychological Assessment Resources.

Hughey, K., \& Hughey, J. (2009). Foundations of career advising. In K. Hughey, D. Nelson, J. Damminger, B. McCalla-Wriggins (Eds.), The handbook for career advising (pp. 1-18). 
San Francisco, CA: Jossey Bass.

Iachan, R. (1984). A family of differentiation indices. Psychometrika, 49, 217-222.

Johnson, J. (2013). Assessing academic risk of student-athletes: Applicability of the NCAA graduation risk overview model. NACADA Journal, 33(2), 76-89.

Jones, F., Brooks, D., \& Mak, J. (2008). Examining sport management programs in the United States. Sport Management Review, 11, 77-91.

King, B. (2009, August 24). New lessons to learn: Sport management programs evolve to meet demand, economic realities. Street \& Smith’s SportsBusiness Journal.

Kjeldsen, E. (1990). Sport management careers: A descriptive analysis. Journal of Sport Management, 4, 121-132.

Kristof, A. (1996). Person-organization fit: An integrative review of its conceptualizations, measurement, and implications. Personnel Psychology, 49, 1-49.

Lovelock, C., \& Gummesson, E. (2004). Whither services marketing?: In search of a new paradigm and fresh perspectives. Journal of Service Research, 7(1), 20-41.

Mathner, R. \& Martin, C. (2012). Sport management graduate and undergraduate students' perceptions of career expectations in sport management. Sport Management Education Journal, 6, 21-31.

Maurer, T., \& Tarulli, B. (1997). Managerial work, job analysis, and Holland's RIASEC vocational environment dimensions. Journal of Vocational Behavior, 50, 365-381.

Nauta, M. (2010). The development, evolution, and status of Holland's theory of vocational personalities: Reflections and future directions for counseling psychology. Journal of Counseling Psychology, 57(1), 11-22.

Nauta, M. (2013). Holland's theory of vocational choice and adjustment. In S.D. Brown \& R.W. 
Lent (Eds.), Career development and counseling: Putting theory and research to work. ( $2^{\text {nd }}$ ed., pp. 55-82). Hoboken, NJ: John Wiley \& Sons.

Nye, C., Su, R., Rounds, J., \& Drasgow, F. (2012). Vocational interests and performance: A quantitative summary of over 60 years of research. Perspectives on Psychological Science, 7(4), 384-403.

O*NET Online. (2015). Retrieved from https://www.onetonline.org/

Pedersen, P., \& Thibault, L. (2014). Contemporary sport management ( $5^{\text {th }}$ ed.). Champaign, IL: Human Kinetics.

Pierce, D., Lawrence, H., \& Kaburakis, A. (2011). Creating synergy between athletics compliance and academic programs: Students in the compliance office. Journal of Contemporary Athletics, 5(3), 183-201.

Pierce, D., Petersen, J., Clavio, G., \& Meadows, B. (2012). Content analysis of sport ticket sales job announcements. Sport, Business, and Management: An International Journal, 2(2), $137-155$.

Pierce, D., Wanless, E., \& Johnson, J. (2014). Assessing outcomes of a realistic major preview in an introductory sport management course. SCHOLE: A Journal of Leisure Studies \& Recreation Education, 29(1), 60-74.

Ross, S., \& McCullough, B. (2014). Developing a professional perspective. In P.M. Pedersen and L. Thibault (Ed.), Contemporary Sport Management ( $5^{\text {th }}$ ed., pp. 34-55). Champaign, IL: Human Kinetics.

Rounds, J., Smith, T., Hubert, L., Lewis, P., \& Rivkin, D. (1999). Development of occupational interest profiles for O*NET. Raleigh, NC: Natioanl Center for O*NET Development.

Rounds, J., Su, R., Lewis, P., \& Rivkin, D. (2013). Occupational interest profiles for new and 
emerging occupations in the $O^{*}$ NET system: Summary. Raleigh, NC: Natioanl Center for O*NET Development.

Schwab, K., Dustin, D., Legg, E., Timmerman, D., Wells, M., \& Arthur-Banning, S. (2013). Choosing sport management as a college major. SCHOLE: A Journal of Leisure Studies and Recreation Education, 28(2), 16-27.

Spokane, A., Luchetta, E., \& Richwin, M. (2002). Holland's theory of personalities and work environments. In D. Brown \& Associates (Eds.), Career choice and development ( ${ }^{\text {th }}$ ed., pp. 373-426). San Francisco, CA: Jossey Bass.

Teamwork Online. (2014). White paper: Sports hiring 2014. Shaker Heights, OH: Teamwork Online.

Todd, S., \& Andrew, D. (2008). An exploratory investigation of sport management students' attraction to sport jobs. International Journal of Sport Management and Marketing, 4(4), 323-337.

Upperman, P., \& Church, T. (1995). Investigating Holland's typology theory with Army occupational specialties. Journal of Vocational Behavior, 47, 61-75.

Wong, G. (2009). The comprehensive guide to careers in sports. Sudbury, MA: Jones and Bartlett.

Wong, G. (2014). The path to the athletic director's office. Street \& Smith's SportsBusiness Journal, 17(9), 32. 
Table 1

Descriptive Summary of Occupational Disciplines on Holland Environments

\begin{tabular}{|c|c|c|c|c|c|c|c|c|c|c|c|c|c|}
\hline \multirow[b]{2}{*}{ Occupational Discipline } & \multirow[b]{2}{*}{$\mathbf{N}$} & \multicolumn{2}{|c|}{ Realistic } & \multicolumn{2}{|c|}{ Investigative } & \multicolumn{2}{|c|}{ Artistic } & \multicolumn{2}{|c|}{ Social } & \multicolumn{2}{|c|}{ Enterprising } & \multicolumn{2}{|c|}{ Conventional } \\
\hline & & $\mathbf{M}$ & SD & $\mathbf{M}$ & SD & $\mathbf{M}$ & SD & $\mathbf{M}$ & SD & $\mathbf{M}$ & SD & $\mathbf{M}$ & SD \\
\hline Academic advisement & 57 & 3.18 & 2.28 & 6.75 & 3.08 & 5.74 & 1.93 & 11.58 & 1.15 & 8.40 & 2.56 & 9.04 & 2.54 \\
\hline Athletic director & 37 & 6.54 & 2.28 & 6.76 & 3.36 & 6.16 & 2.18 & 11.41 & 1.86 & 10.86 & 2.00 & 8.95 & 2.73 \\
\hline Athletic trainer & 123 & 10.67 & 1.89 & 9.15 & 2.83 & 5.07 & 1.26 & 11.24 & 1.58 & 7.79 & 2.67 & 8.37 & 2.62 \\
\hline Business management & 30 & 5.17 & 3.78 & 5.63 & 3.58 & 4.77 & 2.03 & 8.30 & 3.59 & 7.43 & 3.67 & 9.23 & 2.92 \\
\hline Compliance & 47 & 3.17 & 2.68 & 7.94 & 2.63 & 4.70 & 1.37 & 9.62 & 2.35 & 8.26 & 2.67 & 10.02 & 2.52 \\
\hline Development & 40 & 4.70 & 2.71 & 5.58 & 2.96 & 6.17 & 1.62 & 11.35 & 1.70 & 10.88 & 2.22 & 9.95 & 3.00 \\
\hline Equipment manager & 21 & 12.10 & 0.83 & 5.52 & 3.17 & 5.33 & 1.39 & 9.86 & 1.98 & 8.33 & 2.39 & 9.71 & 2.35 \\
\hline Event and facility management & 43 & 10.49 & 3.02 & 5.49 & 2.59 & 4.88 & 1.38 & 9.98 & 2.82 & 8.60 & 2.63 & 8.65 & 2.72 \\
\hline Marketing & 38 & 7.13 & 3.02 & 4.95 & 3.44 & 7.45 & 2.69 & 9.58 & 2.84 & 10.42 & 2.26 & 7.47 & 3.00 \\
\hline Sales & 17 & 5.12 & 2.89 & 5.18 & 3.09 & 6.18 & 2.27 & 9.71 & 2.71 & 11.24 & 1.52 & 7.88 & 2.93 \\
\hline Sports information & 57 & 7.12 & 3.17 & 5.95 & 2.63 & 7.26 & 2.08 & 9.65 & 2.37 & 8.95 & 2.86 & 8.91 & 2.25 \\
\hline Team operations & 17 & 8.06 & 3.23 & 6.12 & 3.31 & 5.59 & 2.00 & 10.06 & 2.90 & 9.41 & 2.85 & 8.65 & 3.26 \\
\hline Ticketing/Box office & 23 & 5.26 & 3.05 & 4.48 & 2.57 & 4.30 & 1.30 & 10.48 & 1.47 & 10.43 & 2.27 & 9.83 & 1.56 \\
\hline Video & 15 & 10.07 & 2.60 & 3.53 & 2.62 & 7.00 & 2.24 & 8.13 & 3.11 & 6.93 & 2.99 & 6.27 & 2.34 \\
\hline Overall & 565 & 7.27 & 3.95 & 6.64 & 3.33 & 5.69 & 2.00 & 10.39 & 2.41 & 8.90 & 2.86 & 8.69 & 2.72 \\
\hline
\end{tabular}

Note: Mean scores can range from 0-13. 
Table 2

Summary of Holland Diagnostics for Occupational Disciplines

\begin{tabular}{lllll}
\hline Occupational Discipline & Holland Code & Consistency & Iachan Index & Differentiation \\
\hline Academic advisement & SCE & MEDIUM & 1.8 & Moderately defined \\
Sales & ESC & HIGH & 1.6 & Moderately defined \\
Equipment manager & RSC & LOW & 1.5 & Moderately defined \\
Development & SEC & HIGH & 1.4 & Moderately defined \\
Athletic director & SEC & HIGH & 1.3 & Moderately defined \\
Ticketing/Box office & SEC & HIGH & 1.3 & Moderately defined \\
Overall College Sports & SEC & HIGH & 1.3 & Moderately defined \\
Video & RSA/E & LOW & 1.2 & Moderately defined \\
Business management & CSE & MEDIUM & 1.1 & Moderately defined \\
Marketing & ESC/A & HIGH & 1.0 & Moderately defined \\
Athletic trainer & SRI & LOW & 0.9 & Not well defined \\
Sports information & SEC & HIGH & 0.8 & Not well defined \\
Team operations & SEC & HIGH & 0.7 & Not well defined \\
Compliance & CSE & MEDIUM & 0.6 & Not well defined \\
Event and facility management & RSC/E & LOW & 0.6 & Not well defined \\
\hline
\end{tabular}


Table 3

Post hoc Results

\begin{tabular}{|c|c|c|c|c|c|c|c|c|c|}
\hline \multicolumn{5}{|c|}{ Realistic } & \multicolumn{5}{|c|}{ Investigative } \\
\hline Rank & $\begin{array}{l}\text { Occupational } \\
\text { Discipline }\end{array}$ & M & SD & $\begin{array}{l}\text { Significant } \\
\text { Results }\end{array}$ & Rank & $\begin{array}{l}\text { Occupational } \\
\text { Discipline }\end{array}$ & $\mathrm{M}$ & SD & $\begin{array}{l}\text { Significant } \\
\text { Results }\end{array}$ \\
\hline 1 & Equipment mgr & 12.10 & 0.83 & $>6-14$ & 1 & Athletic trainer & 9.15 & 2.83 & $>3-4,6-14$ \\
\hline 2 & Athletic trainer & 10.67 & 1.89 & $>6-14$ & 2 & Compliance & 7.94 & 2.63 & $>9-10,13-14$ \\
\hline 3 & Event/facility mgt & 10.49 & 3.02 & $>6-14$ & 3 & Athletic director & 6.76 & 3.36 & \\
\hline 4 & Video & 10.07 & 2.60 & $>9-14$ & 4 & Academic advisement & 6.75 & 3.08 & \\
\hline 5 & Team operations & 8.06 & 3.23 & $>13-14$ & 5 & Team operations & 6.12 & 3.31 & \\
\hline 6 & Marketing & 7.13 & 3.02 & $>13-14 ;<1-3$ & 6 & Sports information & 5.95 & 2.63 & \\
\hline 7 & Sports information & 7.12 & 3.17 & $>13-14 ;<1-3$ & 7 & Business mgt & 5.63 & 3.58 & \\
\hline 8 & Athletic director & 6.54 & 2.28 & $>13-14 ;<1-3$ & 8 & Development & 5.58 & 2.96 & \\
\hline 9 & Ticketing/Box office & 5.26 & 3.05 & $<1-4$ & 9 & Equipment mgr & 5.52 & 3.17 & $<1-2$ \\
\hline 10 & Business mgt & 5.17 & 3.78 & $<1-4$ & 10 & Event/facility mgt & 5.49 & 2.59 & $<1-2$ \\
\hline 11 & Sales & 5.12 & 2.89 & $<1-4$ & 11 & Sales & 5.18 & 3.09 & \\
\hline 12 & Development & 4.70 & 2.71 & $<1-4$ & 12 & Marketing & 4.95 & 3.44 & \\
\hline 13 & Academic advisement & 3.18 & 2.28 & $<1-9$ & 13 & Ticketing/box office & 4.48 & 2.57 & $<1-2$ \\
\hline 14 & Compliance & 3.17 & 2.68 & $<$ top $1-8$ & 14 & Video & 3.53 & 2.62 & $<1-2$ \\
\hline
\end{tabular}

Note: Mean scores can range from 0-13. 
Table 4

Post hoc Results

\begin{tabular}{|c|c|c|c|c|c|c|c|c|c|}
\hline \multicolumn{5}{|c|}{ Artistic } & \multicolumn{5}{|c|}{ Social } \\
\hline Rank & $\begin{array}{l}\text { Occupational } \\
\text { Discipline }\end{array}$ & M & SD & $\begin{array}{l}\text { Significant } \\
\text { Results }\end{array}$ & Rank & $\begin{array}{l}\text { Occupational } \\
\text { Discipline }\end{array}$ & M & SD & $\begin{array}{l}\text { Significant } \\
\text { Results }\end{array}$ \\
\hline 1 & Marketing & 7.45 & 2.69 & $>10-14$ & 1 & Academic advisement & 11.58 & 1.15 & $>10-14$ \\
\hline 2 & Sports information & 7.26 & 2.08 & $>9-14$ & 2 & Athletic director & 11.41 & 1.86 & $>10-11,13-14$ \\
\hline 3 & Video & 7.00 & 2.24 & $>12-14$ & 3 & Development & 11.35 & 1.70 & $>10-11,13-14$ \\
\hline 4 & Sales & 6.18 & 2.27 & & 4 & Athletic trainer & 11.24 & 1.58 & $>10-11 ; 13-14$ \\
\hline 5 & Development & 6.17 & 1.62 & & 5 & Ticketing/Box office & 10.48 & 1.47 & \\
\hline 6 & Athletic director & 6.16 & 2.18 & & 6 & Team operations & 10.06 & 2.90 & \\
\hline 7 & Academic advisement & 5.74 & 1.93 & & 7 & Event/facility mgt & 9.98 & 2.82 & \\
\hline 8 & Team operations & 5.59 & 2.00 & & 8 & Equipment mgr & 9.86 & 1.98 & \\
\hline 9 & Equipment mgr & 5.33 & 1.39 & & 9 & Sales & 9.71 & 2.71 & \\
\hline 10 & Athletic trainer & 5.07 & 1.26 & & 10 & Sports information & 9.65 & 2.37 & $<1-4$ \\
\hline 11 & Event/facility mgt & 4.88 & 1.38 & $<1-2$ & 11 & Compliance & 9.62 & 2.35 & $<1-4$ \\
\hline 12 & Business mgt & 4.77 & 2.03 & $<1-3,5$ & 12 & Marketing & 9.58 & 2.84 & $<1$ \\
\hline 13 & Compliance & 4.70 & 1.37 & $<1-3,5$ & 13 & Business mgt & 8.30 & 3.59 & $<1-4$ \\
\hline 14 & Ticketing/box office & 4.30 & 1.30 & $<1-3,5-6$ & 14 & Video & 8.13 & 3.11 & $<1-4$ \\
\hline
\end{tabular}

Note: Mean scores can range from 0-13. 
Table 5

Post hoc Results

\begin{tabular}{|c|c|c|c|c|c|c|c|c|c|}
\hline \multicolumn{5}{|c|}{ Enterprising } & \multicolumn{5}{|c|}{ Conventional } \\
\hline Rank & $\begin{array}{l}\text { Occupational } \\
\text { Discipline }\end{array}$ & $\mathrm{M}$ & SD & $\begin{array}{l}\text { Significant } \\
\text { Results }\end{array}$ & Rank & $\begin{array}{l}\text { Occupational } \\
\text { Discipline }\end{array}$ & $\mathrm{M}$ & SD & $\begin{array}{l}\text { Significant } \\
\text { Results }\end{array}$ \\
\hline 1 & Sales & 11.24 & 1.52 & $>8-14$ & 1 & Compliance & 10.02 & 2.52 & $>10-11,13-14$ \\
\hline 2 & Development & 10.88 & 2.22 & $>8-14$ & 2 & Ticketing/Box office & 9.83 & 1.56 & $>14$ \\
\hline 3 & Athletic director & 10.86 & 2.00 & $>8-14$ & 3 & Equipment mgr & 9.71 & 2.35 & \\
\hline 4 & Marketing & 10.43 & 2.27 & $>9,11-14$ & 4 & Business mgt & 9.23 & 2.92 & \\
\hline 5 & Ticket/Box office & 10.42 & 2.26 & $>12,14$ & 5 & Academic advisement & 9.04 & 2.54 & \\
\hline 6 & Team operations & 9.41 & 2.85 & & 6 & Athletic director & 8.95 & 2.73 & \\
\hline 7 & Sports information & 8.95 & 2.86 & & 7 & Sports information & 8.91 & 2.25 & \\
\hline 8 & Event/facility mgt & 8.60 & 2.63 & $<1-3$ & 8 & Event/facility mgt & 8.65 & 2.72 & \\
\hline 9 & Academic advisement & 8.40 & 2.56 & $<1-4$ & 9 & Team operations & 8.65 & 3.26 & \\
\hline 10 & Equipment mgr & 8.33 & 2.39 & $<1-3$ & 10 & Athletic trainer & 8.37 & 2.62 & $<1$ \\
\hline 11 & Compliance & 8.26 & 2.67 & $<1-4$ & 11 & Development & 7.95 & 3.00 & $<1$ \\
\hline 12 & Athletic trainer & 7.79 & 2.67 & $<1-5$ & 12 & Sales & 7.88 & 2.93 & \\
\hline 13 & Business mgt & 7.43 & 3.67 & $<1-4$ & 13 & Marketing & 7.47 & 3.00 & $<1$ \\
\hline 14 & Video & 6.93 & 3.11 & $<1-5$ & 14 & Video & 6.27 & 2.34 & $<1-5$ \\
\hline
\end{tabular}

Note: Mean scores can range from 0-13. 
$\mathbf{R}$ - The Realistic environment is characterized by systematic use of objects, tools, and machines for practical, concrete activities. Realistic individuals enjoy hands-on or manual activities and prefer to work with things rather than ideas or people.
I - The Investigative environment is characterized by the use of analytical, scientific, and verbal skills that result in problem solving or knowledge creation. Investigative individuals are intellectual and observant and drawn to ambiguous challenges that require logic to solve highly complex or abstract.
C - The Conventional environment is characterized by the systematic manipulation of things or numbers in a precise way such as keeping records and organizing data according to prescribed plans. Conventional individuals are careful and conscientious and prefer working within an established chain of command to execute prescribed tasks. Conventional types enjoy manipulating data, organizing schedules, and operating office equipment.
$\mathbf{E}$ - The Enterprising environment is characterized by persuasion and manipulation of people to attain organizational or personal goals. Enterprising individuals are ambitious and self-confident and enjoy tasks that require them to persuade others, often times in leadership roles.
S - The Social environment is characterized by social activities and interpersonal skills that inform, train, enlighten, or help other people. Social individuals are concerned with the welfare of others and enjoy helping, training, and developing other people. Social types seek to work as part of a team and solve problems by working with others. 